rally; but since the heart is powerless to act on account of the difficulty which exists in the lungs, the further congestion occasioned by the inverted position of the body merely aggra vates the existing evil ; and, thirdly, that the venous blood in the neck and arms which gets to the brain, in consequence of the depression of the head, only deepens the coma which already exists. Now, there is no doubt that the treatment of drowned persons by inverting the body is very ancient. The attempt to restore from drowning by inverting the body is depicted on the Egyptian monuments. The exploits of Rameses the Great in Assyria are represented in the sculptures on the tomb of Osymandyos; some of the defeated enemy are carrying the corpse of their chief, who was drowned in the river Euphrates, and are in vain endeavouring to restore life by holding the head downwards to expel the water which was believed to have entered the body. It is probable that this kind of treatment continued down to comparatively modern times; for in the year 1774 the Royal Humane Society ordered that the body should not be carried on anyone's shoulders with the head hanging downwards, nor rolled upon the ground, nor over a barrel, nor lifted by the heels, and it is added that "these methods are injurious and often destroy the small remains of life." Seeing, then, how injurious and apparently useless this method of treat ment appears on physiological grounds, may it not have been revived with another object in view-namely, that by this means the heavy vapour of chloroform might be thus poured out from the lungs by gravitation? It is, however, very doubtful whether the vapour of chloroform, still less that of ether, at the temperature of the body, can be ejected from the lungs in this way, for some time since $I$ performed a series of experiments in order to ascertain whether it would be possible to remove water (which is much heavier than the vapour of chloroform) from the lungs of drowned persons (supposing for the sake of argument that it had gained admission there) by placing the body in any of the positions which have been recommended for the attainment of this object. I injected small and large quantities of water into the lungs through the windpipe by a forcing syringe, and then endeavoured to remove it by placing the body in various positions, such as reclining on the face, rolled from supine to prone, held up by the feet, \&c., but without success, although there was less difficulty with regard to fluids in the stomach; but this is not of much consequence, as the water swallowed is usually vomited on the return of consciousness.

In the treatment of the apparently dead the following positions of the body have had their advocates-namely, resting horizontally on the face, on the side, on the back, alternately prone and supine, inverted, sitting up, bent forwards and bent backwards. Dr. E. Watson recommends the "supine and horizontal"; but experience appears to teach that the most suitable position is that of lying on the back, the body inclining a little from the feet upwards, the shoulders and head slightly raised and supported on a firm cushion. This position is favourable for the relief of congestion of the heart and head, and both sides of the chest are free to expand, and this affords the best chance of restoration from apparent death.

Clapham Common.

\section{ON REFRACTURE OF THE PATELLA.}

BY H. PARSON, M.R.C.S., L.R.C.P. ED.

ASSISTANT MEDICAL OFFICER, ROYAL SURREY COUNTY HOSPITAL.

PERHAPs the following particulars of a case of refracture of the patella, together with a description of the appliances used during the treatment, may be of interest to some of your readers.

In December, 1874, Mr. fractured his left patella at the junction of the upper and middle thirds. In October, 1880 , he fractured the same bone at the junction of the middle and lower thirds; and in August, 1882, he refractured the left patella at the seat of the last injury - viz, at the junction of the middle and lowt $x$ thirds. This last accident occurred August 6th whilst staving at Amsterdam. He was seen by a local surgeon who applied suitable splints, and the patient started for England on August 8th, reaching his home on the 9th. I was called in on the 11 th and found considerable swelling over the joint with about three-quarters of an inch of separation between the fragments; the amount of separation which existed directly after the accident I could not ascertain. The lower fragment was small and very movable. He was wearing a leather splint with side supports to which were strapped two semilunar soft leather pads. By drawing the pads together and fastening them I got the frag. ments into close apposition, and the patient continued to wear this contrivance until the primary inflammation had subsided. I then devised the appliance of which an illus tration is here given, and which is manufactured by Messrs.

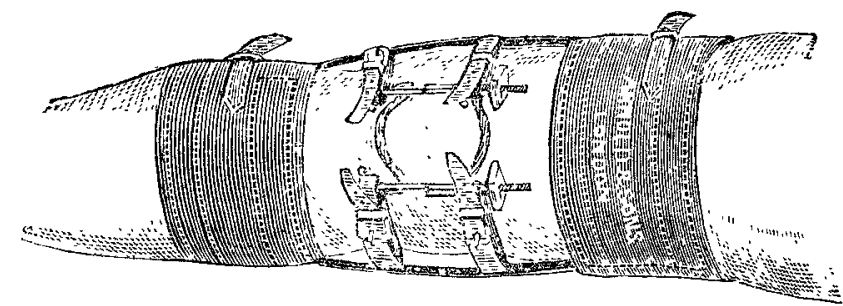

Arnold and Sons of West Smithfield. It consists of two semilunar pieces made of some round, narrow, unyielding material, shaped to fit the edges of the lower and upper fragments. One piece slides on the other and admits of closing and separating them by means of screws and without any other movement; so that, when adjusted and firmly strapped to the side supports of a suitable splint prepared for it the upper and lower pieces are perfectly rigid one with the other. It is then almost impossible for the patella to slip out of position. The semilunar pieces being narrow, they form grooves for themselves behind the fragments, and have a tendency to run under the bone instead of over-riding as most other appliances do ; thus the pieces are kept firmly in good position in their proper plane and have no tendency to tilt. This apparatus was applied about the end of the third week from the date of the accident, and the patient removed to the couch. At the end of the fourth week he came downstairs with assistance, and went out in a Bath chair. At the fifth week he walked round the garden with the aid of sticks. At the seventh week be walked a mile with one stick. At the end of the eighth week he returned to business, walking to and fro, that is, two miles daily. He could walk well wearing the appliance, and experienced very little inconvenience, and to the best of my knowledge the fragments never slipped once during the twenty weeks that he wore the splint. The pressure was relieved at times by small tufts of cotton-wool, and by wearing an old splint at night, but during the latter part of the time nothing was worn at night, thus abrasions from continued pressure were avoided entirely.

The patient now walks well, and is not particular as to distance, but still wears a contrivance to support the knee-cap and limit the movements of the joint. The advantages claimed for the appliance are these :-

1. As soon as the primary inflammation has subsided and the apparatus firmly and properly adjasted, the patient can begin to move about, and in a short time follow his usual business pursuits.

2. The long confinement to bed is avoided; thus the patient retains his health and strength, and the condition is more favourable to the repair of tissues.

3. Easy adjustment of fragments and the keeping of them in good position, without fear of slipping when the patient is walking.

4. The slight movement of knee in walking prevents a stiff joint, and keeps up sufficient activity in the parts to complete the union.

Lastly, but not least, as far as the patient is concerned, the reduction of the "doctor's bill," as he will require much less attention.

I consider the case here mentioned to be a good test case for trying the merits of the invention; for if the surgeon can secure a good union in a refracture and under such adverse circumstances, surely the results will be far superior in the case of primary fracture.

Guildford.

AN inquest was held on the 14th inst. at Newcastle under.Lyne touching the death of Mr. Richard Corston Wade, surgeon, formerly of Manchester. The deceased was, i appeared from the evidence, in the habit of taking landanum. On the 12th inst. he took a larger quantity than usual and fell into a comatose condition from which he never recovered. The jury returned a verdict that "Death was caused by an overdose of laudanum." 